ARTIGOS

\title{
As noções de experiência e vivência no currículo cultural de Educação Física: ressonâncias nietzschianas e foucaultianas ${ }^{12} 3$
}

\section{The notion of experience in the cultural curriculum of Physical Education: Nietzschean and Foucaultian resonances ${ }^{4}$}

Mário Luiz Ferrari Nunes (i)

Fidel Machado de Castro Silva (ii)

Marina Contarini Boscariol (iii)

Marcos Garcia Neira (iv)

\begin{abstract}
(i) Universidade Estadual de Campinas - UNICAMP, Campinas, SP, Brasil. https://orcid.org/00000003-0680-5777, mario.nunes@fef.unicamp.br.

(ii) Universidade Estadual de Campinas - UNICAMP, Campinas, SP, Brasil. Universidade Federal do Ceará - UFC, Fortaleza, CE, Brasil. https:/ / orcid.org/0000-0002-8289-7733,

fidel_machado@yahoo.com.br.

(iii) Universidade Estadual de Campinas - UNICAMP, Campinas, SP, Brasil. https:/ / orcid.org/00000002-6386-678X, marina.boscariol@yahoo.com.br.

(iv) Universidade de São Paulo - USP, São Paulo, SP, Brasil. https://orcid.org/0000-0003-1054-8224, mgneira@usp.br.
\end{abstract}

Resumo:
Influenciado pelas teorias pós-críticas da educação, o currículo cultural da Educação
Física emerge como possibilidade de enfrentamento das condições sociais que
insistem em homogeneizar sujeitos, colonizar desejos e regular as formas de viver.
Neste artigo, situamos a apropriação das noções conceituais de experiência e
vivência na pedagogia moderna e as implicações de suas ressonâncias nietzschianas
e foucaultianas para a pedagogia cultural da Educação Física. Tencionamos torná-la
um espaço de resistência às imposições castradoras da vida, a fim de potencializar
possibilidades transgressoras dos limites normativos estabelecidos.
Palavras-chave: educação física, currículo, experiência, vivência, educação

\footnotetext{
${ }^{1}$ Editor responsável: Alexandre Filordi de Carvalho. https://orcid.org/0000-0003-4510-9440

2 Apoio: Fundação de Amparo à Pesquisa do Estado de São Paulo (Fapesp). Processo no 2016/11237-0.

${ }^{3}$ Normalização, preparação e revisão textual: Douglas Mattos (Tikinet) - revisao@tikinet.com.br

4 Os termos "vivência" e "experiência" têm a mesma referência em inglês. Optamos por grafar apenas o termo "experiência" no título e resumo traduzidos.
} 


\title{
pro.posições
}

$e$-ISSN 1980-6248

http://dx.doi.org/10.1590/1980-6248-2019-0047

\begin{abstract}
:
Influenced by the post-critical theories of education, the cultural curriculum of Physical Education emerges as a possibility of confronting social conditions that insist on homogeniring subjects, colonizing desires and regulating people lives. In this article, we situate the appropriation of conceptual notion of experience in modern pedagogy and the implications of their uses supported by Nietssche and Foucault on Physical Education cultural pedagogy. We intend to make them into resistance's spaces to impositions ways of living, in order to potentialize transgressive possibilities of established normative limits.
\end{abstract}

Keywords: physical education, curriculum, experience, education

\section{Introdução}

Embora sua produção possa ser considerada recente, o denominado currículo cultural (CC) da Educação Física tem marcado presença em eventos acadêmicos, linhas editoriais, concursos públicos para professores, referências bibliográficas em disciplinas acadêmicas, orientações curriculares dos sistemas de ensino estaduais, municipais e privados e, principalmente, pautando a ação docente no chão da escola. Não obstante as obras de Neira e Nunes $(2006,2009$ a e 2009b) sejam identificadas como os primeiros registros da proposta, cabe dizer que, coadunando com seus campos teóricos, não existe qualquer privilégio de autoria.

Compreende-se que o CC é uma produção permanente que acontece na trama entre os docentes que atuam na Educação Superior e Básica, os discentes, a cultura escolar e a cultura corporal. Como qualquer outra forma de conhecimento, o CC é uma invenção que se dá em meio às condições da vida.

Na visão de Nietzsche, o conhecimento sobrevém dos jogos de força, não é algo natural, simples ou uma relação causal entre o sujeito e o objeto a ser desvelado por um sujeito racional. Tampouco pode ser colocado à prova com o recurso de métodos científicos. O conhecimento, para o filósofo alemão, não consegue esconder as correlações de forças que o produzem, os interesses e as condições contingenciais que o cercam. Isso implica dizer que o conhecimento 


\section{pro.posıções}

$e$-ISSN 1980-6248

http://dx.doi.org/10.1590/1980-6248-2019-0047

não é da ordem da descoberta, tampouco se remete a um sujeito que esteja na sua origem. É o contexto histórico que disponibiliza as condições de possibilidade da sua existência.

O CC decorre do enfrentamento diário das questões colocadas pela escola diante das circunstâncias da sociedade contemporânea, quais sejam: uma sociedade multicultural e desigual, que expõe a todo instante os sujeitos a situações conflitantes decorrentes de privilégios históricos para poucos. Situações que causam formas recorrentes de dominação e opressão, ante representantes de grupos que lutam pela igualdade de direitos e pelo direito à diferença. Lutam, também, por menos obediência às formas hegemônicas de regulação moral, política, social, corporal. Lutam para escapar da representação, da identidade imposta. Lutam pelo exercício de práticas de liberdade, pela afirmação da vida.

Essas lutas também questionam a escola. Enquanto projeto da Modernidade, ela se mantém como instituição que reforça a concepção de sujeito universal projetada pelo Iluminismo. Mudam as suas tecnologias, porém mantém-se a ênfase no governo da conduta dos outros, pautado no processo de homogeneização cultural que, na atualidade, é o projeto neoliberal. Não à toa, a escola é constantemente abalada pela heterogeneidade de seus sujeitos e, nesse jogo de forças, emerge o CC como possibilidade, limitada pela regulação escolar, para potencializar a vida. Sumariamente, pode-se dizer que a proposta objetiva produzir outras formas de explicar e agir nesse turbilhão cultural, a fim de superar as condições que colonizam desejos e imobilizam ações. O desejo é transgredir os limites impostos e fomentar outras possibilidades de existência.

Como se sabe, o CC se baseia nas teorias pós-críticas ${ }^{5}$, concebe o movimento humano como linguagem e toma o corpo como um texto passível de leitura e escritura, o que implica a produção, a comunicação e a negociação de sentidos. O pensamento pós questiona a razão da ciência (sem negar a sua validade) como árbitro único e definitivo do que venha a ser conhecimento. Abre portas para as incertezas e considera as perspectivas da realidade produzida por grupos culturais diversos, a fim de compreender os regimes de verdade e as relações de poder que definem a realidade, produzem assimetrias sociais e formas de resistência em cada

\footnotetext{
${ }^{5}$ Para Silva (1999), as teorias pós-críticas colocam em dúvida alguns pressupostos das teorias críticas e expandem seus limites. A analítica do poder deixa de ser centrada no Estado, sem, no entanto, negar sua força. Ampliam as análises para outras formas de dominação presentes nas microfísicas das relações sociais. Elas dizem respeito aos modos como o sujeito é constituído em meio aos discursos que produzem regimes de verdade e efeitos específicos de poder que incidem nas técnicas pelas quais o sujeito aplica esses regimes a si mesmo, que impactam o seu "eu" $\mathrm{e}$ as identidades que assumem.
} 


\section{pro.posições}

$e$-ISSN 1980-6248

http://dx.doi.org/10.1590/1980-6248-2019-0047

época e lugar. O termo pós questiona os limites fixos da explicação para pensar em termos de condições para a mudança, para a abertura, para a transgressão dos limites estabelecidos.

As bases epistemológicas e didático-pedagógica do CC indicam processos contínuos de significação e ressignificação de conceitos e formas de dizer. Fatos que demonstram o caráter transgressor dos seus próprios limites e marcam seu território nas filosofias da diferença, reconhecidas nos trabalhos de Foucault, Derrida, Deleuze e Guattari, cujas produções foram influenciadas pelo pensamento de Nietzsche.

É possível observar esses processos nas diversas teses, dissertações, artigos científicos, relatos de experiência, vídeos, livros e capítulos que abordam o CC. Notam-se nesses "ditos e escritos" termos caros à pedagogia moderna tradicional como planejamento (Nunes, 2018), método (Neira, 2011), avaliação (Escudero, 2011), registro (Müller, 2016), e outros caros à pedagogia moderna crítica como participação (Lima, 2007), problematização e tematização (Santos \& Neira, 2016), ancoragem social dos conhecimentos, justiça curricular, etnografia, mapeamento, ressignificação, ampliação e aprofundamento (Neira \& Nunes, 2009a, 2009b; Neira, 2011) sem, no entanto, fechá-los em uma identidade unívoca. Também é possível notar o esforço para anunciar o que se pretende.

Em todos os trabalhos que abordam o CC e em muitas obras que dão vida à proposta, o termo "vivência" recebe o devido destaque, mas sem maiores explicações do que se quer dizer com isso. Mais recentemente, Nunes (2018) incorporou ao discurso sobre essa perspectiva de ensino outro termo bastante recorrente na educação - "experiência" - acrescentando-lhe o complemento "de si”. Não há como negar que o fato de os significantes "vivência" e "experiência" estarem dispersos na literatura pedagógica de matriz psicológica ou fenomenológica, aliado à carência de explicações mais detalhadas do que os distingue em relação à teorização pós-crítica, tenha reverberado em ações didáticas que beiram a instrumentalização. $\mathrm{Na}$ tentativa de diluir a confusão instalada, o presente artigo situa a apropriação da terminologia na pedagogia moderna e as implicações de suas ressonâncias nietzschianas e foucaultianas para a pedagogia cultural da Educação Física. 


\section{pro.posıções}

http://dx.doi.org/10.1590/1980-6248-2019-0047

\section{$e$-ISSN 1980-6248}

\section{Na pedagogia moderna...}

O significante "experiência" foi enfatizado pela teoria empirista do conhecimento de John Locke (1999), em meados do século XVII. A experiência seria o que supre a mente, algo como uma impressão num papel em branco. Apenas ela permitiria a aquisição da razão e do conhecimento. Segundo o filósofo inglês, tanto a educação poderia ser vista como experiência, como a experiência ser vista como educação, pois seria a experiência a própria fonte do conhecimento. Ela ofereceria à mente a sensação ou a reflexão para o entendimento das coisas do mundo. Logo, o trabalho pedagógico consistiria em cuidar da experiência para que fosse fecunda e efetiva na educação dos homens (Noguera-Ramírez, 2011).

No século seguinte, outro filósofo, o suíço Jean-Jacques Rousseau, enfatizou o caráter ativo da educação baseada em experiências. Ao tentar e errar muitas vezes, as crianças apreenderiam o conhecimento por si mesmas. A experiência seria uma espécie de autorregulação que resultaria em crescimento e desenvolvimento. Anos depois, o pedagogo alemão John Herbart afirmou a existência de duas fontes oficias de conhecimento: a experiência e o convívio social. As atividades formuladas de maneira sistemática permitiriam ao indivíduo um conjunto de representações a partir do qual se configuraria o conhecimento (Noguera-Ramírez, 2011).

Essa concepção de experiência sofreu descontinuidades na virada do século XIX para o XX graças às contribuições do psicólogo suíço Édouard Claparède. Sua obra influenciou tanto o movimento da Escola Nova como o cognitivismo de seu discípulo Jean Piaget. Claparède dizia que o ensino deveria basear-se no conhecimento das crianças, que deveriam ocupar o centro do processo, pois, assim, os fenômenos psicológicos seriam abordados a partir do que cada criança faz e do lugar em que atua conforme os padrões de comportamento exigidos. Nesses termos, a pedagogia seria nada mais que a psicologia aplicada. Claparède entendia que a aprendizagem é uma função de adaptação ao ambiente e que toda a atividade é estimulada por uma necessidade a ser satisfeita. Seu trabalho contribuiu de forma decisiva para a adoção do jogo como atividade didática, uma vez que estimula a ação de quem participa.

Raciocínio semelhante fundamentou a proposta pedagógica de John Dewey, para quem a capacidade de aprender adviria da experiência, tendo por efeito a adaptação, o crescimento e o desenvolvimento do indivíduo. O filósofo estadunidense condenou a escola tradicional por tomar a criança como ser passivo e não atender aos seus interesses. Essa perspectiva se apropria da psicologia comportamental para entender a criança como um ser que vive num mundo de 


\section{pro.posıções}

$e$-ISSN 1980-6248

http://dx.doi.org/10.1590/1980-6248-2019-0047

contato limitado. Na sua proposta, os educadores devem organizar essas experiências limitadas e subjetivadas, substituindo-as por realidades concretas através das atividades pedagógicas. Dewey (2002) traz a experiência da criança como ponto de partida para se pensar o ensino, justificando que sem ela há perda do interesse, dificultando a aprendizagem. Mas também é um perigo considerá-la como algo importante em si, pois, na verdade, a experiência da criança é uma ferramenta para desencadear as aprendizagens requeridas pelo mundo real. Para ele, a importância da experiência é dar perspectiva ao método.

Amparada na psicologia, a pedagogia moderna concebeu a aprendizagem como adaptação, resolução de problemas ou, simplesmente, experiência. É o que promoveria a aquisição das habilidades necessárias ao desenvolvimento integral do ser humano (NogueraRamírez, 2011). Por consequência, o método e o controle do espaço e do tempo, somados à compreensão dos modos de ser, pensar e agir das crianças em cada faixa etária, tornaram-se saberes indispensáveis à formação docente. Com raízes profundas na biologia, a pedagogia moderna consiste em aprimorar as capacidades inatas do indivíduo, a fim de que ele atinja fins exteriores e pertinentes às demandas da sociedade. Pedagogias pautadas nestes referenciais visualizam um educar para um mundo que hegemoniza o real, um mundo do trabalho, da produtividade.

Essas ideias fertilizaram o terreno para a emergência das noções de educação permanente, aprendizagem permanente e sociedade da aprendizagem (Drucker, 1999). O sujeito é tido como aprendiz permanente, sempre disposto a aprender. Isso reforça a ideia de pedagogia ativa e a relação entre experiência e desenvolvimento. Não é por acaso que a função da escola tenha se expandido para outras instituições que passaram a operar experiências pedagógicas: fábricas de brinquedos (pedagógicos), shopping centers, buffets, colônias de férias etc.

Pelas constantes demandas que a sociedade globalizada produz, novos discursos são impetrados, produzindo descontinuidades e continuidades para o termo "experiência" e, com isso, para a função da escola. Retoma-se o lema do escolanovismo, e o aprender a aprender passa a ser a finalidade hegemônica da educação contemporânea. Aprender por conta própria possibilita o alcance da autonomia, ao contrário do aprender como resultado da transmissão do conhecimento feito por outrem.

Para um de seus principais porta-vozes, o sociólogo suíço Phillip Perrenoud (2000), o importante é desenvolver competências e, para isso, é preciso ensinar por meio de situações- 


\section{pro.posições}

$e$-ISSN 1980-6248

http://dx.doi.org/10.1590/1980-6248-2019-0047

problema e projetos. É necessário que as experiências sejam complexas e desafiadoras de modo a mobilizarem os conhecimentos já adquiridos pelos estudantes. A pedagogia tem que ser ativa, cooperativa, aberta para a cidade ou para o bairro, seja na zona urbana ou rural. Os professores devem fazer do ato de ensinar um ato de regular situações de aprendizagem, ou seja, regular as experiências para fins utilitários.

A emergência dessas concepções nas teorias e práticas psicopedagógicas concebeu a existência de uma naturalidade no indivíduo, expressa nos seus interesses. Associaram-se também aos conceitos de capital humano, pois a competência é tomada como parte das aptidões, um capital que um indivíduo deve ter, independentemente da classe social, favorecendo a racionalidade política neoliberal (Foucault, 2008). O indivíduo aprendiz escapa da ideia de uma identidade fixa. Ele é um ser destes tempos, flexível e adaptável às condições imprevisíveis da vida e do trabalho. Como afirma Popkewitz (2004), trata-se de um sujeito cosmopolita e inacabado que, enquanto capaz de aprender a aprender, é o único responsável pelas suas ações, seu futuro. No aprender a aprender, desenvolve suas competências para se autoajudar, se autoajustar às demandas destes tempos e, assim, garantir o seu sucesso e felicidade. Afinal, nessa lógica, ele é o único responsável por si mesmo.

A Educação Física foi muito influenciada pela noção de experiência como determinante para a aprendizagem. Diante das críticas ao modelo esportivista dos anos 1970, os aportes da psicologia do desenvolvimento contribuíram para a superação dessa condição e constituíram o movimento renovador da área. Nesse bojo, ao significante "experiência" foi acrescentado "vivência". De forma crescente, ambos passaram a compor os planos de ensino e programas curriculares oficiais, ora como objetivos, ora como estratégias para a aplicação dos jogos psicomotores, tarefas desenvolvimentistas, atividades voltadas para a promoção da saúde e até para ampliar as possibilidades de participação nas práticas corporais mediante a problematização das condições de opressão que interferem nessas práticas.

A análise crítica dos fenômenos da cultura corporal, especialmente o esporte, é a marca das pedagogias críticas da Educação Física (crítico-emancipatória e crítico-superadora). Pautada na fenomenologia, a pedagogia crítico-emancipatória enfatiza que as vivências das práticas corporais permitem ao sujeito que se movimenta descobrir suas significações originárias. Ou seja, permite uma reflexão sobre os fenômenos da consciência ou aquilo que a ela se apresenta, que foram apropriados pelo capitalismo, para, com isso, emancipar-se e atender aos seus 


\section{pro.posições}

$e$-ISSN 1980-6248

http://dx.doi.org/10.1590/1980-6248-2019-0047

interesses pessoais, tidos como verdadeiros. $\mathrm{Na}$ fenomenologia, a vivência é um elemento constitutivo da experiência. A consciência é "uma corrente de experiências vividas. ... Vale-se da noção de intencionalidade para esclarecer a natureza das experiências vividas da consciência" (Husserl, 1996, p. 29). Nesses termos, a vivência só ocorre quando o ser tem a capacidade de interiorizar o mundo a sua volta em imagens objetivas, afetar-se pela condição gerada e atuar sobre ele de modo ativo. Para isso, a vivência, o se movimentar, é a forma de comunicação do homem com o mundo. O que se pretende nessa pedagogia é transcender os limites impostos pelas falsas ilusões e interesses produzidos na sociedade capitalista.

Embora a pedagogia crítico-superadora não apresente definições do que venha a ser vivência e experiência, percebe-se que ela se apropria das definições de John Dewey. Não são poucos os textos que, ao tratar dessa pedagogia, enfatizam a aula de Educação Física como espaço de vivenciar ou experenciar inúmeras práticas corporais, como estratégia para a sua compreensão histórica e política e base para a sua transformação social.

Percebe-se que todas as formas de pensar a vivência e a experiência têm finalidades já determinadas e preestabelecidas, muitas vezes confundindo-se ou fundindo-se entre si, sem a menor distinção.

\section{Em Nietzsche...}

Compreendido como aquele que diz "sim" à vida e ao mundo do acaso, adiantamos que sua obra não oferece uma interpretação unívoca do significante "vivência", cujo traço distintivo é a imbricação direta do termo com a vida. Uma concepção da existência sem pasteurizações faz jus ao vitalismo de Nietzsche e ao contundente pensamento de afirmação do viver e suas vicissitudes sem conotações ou mediações com a moralidade cristã.

\footnotetext{
${ }^{6}$ Em alemão, há dois vocábulos com sentidos diferentes para o termo experiência: Erlebnis e Erfahrung. Erlebnis, como utilizado por Nietzsche, refere-se à vivência com o sentido de promotor de uma ressonância na pessoa. É vivida "de dentro", mobiliza emoção, pois toca sua subjetividade e é anterior a qualquer análise racional. Erfahrung, por sua vez, refere-se à experiência e implica um juízo, uma reflexão, um elemento cognitivo mais forte que a vivência não possui.
} 


\section{pro.posições}

$e$-ISSN 1980-6248

http://dx.doi.org/10.1590/1980-6248-2019-0047

Viesenteiner (2013) discute a relação indubitável do conceito de vivência, em Nietzsche, com a vida na sua dimensão prática; apresenta-o como um contraconceito da razão, ou melhor, uma abertura ao devir sem o crivo explicativo da racionalidade. Um convite à certeza das incertezas que tanto nos amedrontam e nos fazem reféns de um pensamento objetivo e seguro.

Como já foi exposto, o CC da Educação Física não se anuncia como promovedor de vivências. Fosse assim, incorreria numa prepotência incoerente com a interpretação aqui adotada. Destarte, há influência e apoio no conceito e na obra nietzschiana para tentar uma abertura maior ao que aqui compreendemos como vivência. Trata-se de compreender o viver sem recorrer invariavelmente às amarras e ao pretenso objetivo da Modernidade de controlar o incontrolável; da pseudossegurança da escola moderna em garantir um ensino igualitário e transformador da humanidade e baseado na promessa de um futuro inexistente. Ademais, observa-se nas pedagogias decorrentes o esforço para propiciar a mesma vivência a todos os estudantes, o que reflete uma visão utilitária e ilusória da vivência e descarta sua característica individual, estética e imediata com a vida.

As sistematizações são possíveis, mas não possuem garantias de êxito, nem de um controle absoluto sobre a prática e tampouco sobre a vida. Ainda que tenhamos a consciência da limitação das reflexões aqui contidas, compreendemos a farsa universalista da estrutura escolar e, por esse motivo, recorremos à questão prática tão cara à interpretação que adotamos do conceito. Por essa razão, nos debruçaremos sobre as influências da produção do termo e sua recepção na filosofia de Nietzsche.

Há, até a primeira metade do século XIX, no contexto alemão, uma forte associação da vivência à imediata ligação com a vida e uma estreita afinidade com a presença, com o momento presente e a imediatez do instante vivido. Uma oposição à metafísica e ao racionalismo. Tais fatores ocasionam uma intensidade significativa que pode produzir alterações substanciais na existência daquele que sente. Tal condição possui estreita relação com a incapacidade de racionalizar o conteúdo da vivência. Em função disso, o próprio conceito aproxima-se de uma dimensão estética. Um instante imediato e significativo em que algo é sentido (Viesenteiner, 2013). A recepção feita por Friedrich Nietzsche do conceito está imiscuída das características presentes no contexto. Como já é corriqueiro na obra do filósofo, não há uma definição única e absoluta do termo, mas nota-se uma influência significativa desses elementos. 


\section{pro.posıções}

http://dx.doi.org/10.1590/1980-6248-2019-0047

\section{$e$-ISSN 1980-6248}

O que se observa é uma virada de pensamento no que tange à alteração do preciosismo do intelecto para uma primazia do corpo:

Mas o homem já desperto, o sabedor, diz: "Eu sou todo corpo e nada além disso; e alma é somente uma palavra para alguma coisa no corpo".

O corpo é uma grande razão, uma multiplicidade com um único sentido, uma guerra e uma paz, um rebanho e um pastor.

Instrumento de teu corpo é, também, a tua pequena razão, meu irmão, à qual chamas "espírito", pequeno instrumento e brinquedo da tua grande razão.

"Eu", dizes; e ufanas-te desta palavra. Mas ainda maior, no que não querer acreditar - é o teu corpo e a sua grande razão: esta não diz eu, mas faz o eu.

... E sempre o ser próprio escuta e procura: compara, subjuga, conquista, destrói. Domina e é, também, o dominador do eu.

Atrás de teus pensamentos e sentimentos, meu irmão, acha-se um soberano poderoso, um sábio desconhecido - e chama-se o ser próprio. Mora no teu corpo, é o teu corpo.

Há mais razão no teu corpo do que na tua melhor sabedoria. E por que o teu corpo, então, precisaria logo da tua melhor sabedoria? (Nietzsche, 2005, p. 60).

Como desdobramento dessa modificação, o corpo passa a adquirir centralidade na questão da vida orgânica. "A consciência é o último e derradeiro desenvolvimento do orgânico e, por conseguinte, também o que nele é mais inacabado e menos forte” (Nietzsche, 2012, p. 61). Não há um legislador central e onipotente que operacionaliza e comanda todos os estímulos e sensações, mas, sobretudo, há, inicialmente, as sensações. A vivência de algo ou alguma situação não pode ter seu conteúdo construído sob a égide da racionalidade, mas antes deve ser exclusivamente vivido. Viesenteiner (2013) faz uso da expressão "sentido na pele" como forma de ilustrar e definir de maneira mais precisa o termo com a sua relação significativa e imediata com a vida. Aquilo que é sentido de forma imediata e significativa em uma vivência não pode ser capturado pela racionalidade. É o oposto do que geralmente ocorre: racionalizamos para, só então, nos permitirmos. Ou seja, não há uma associação conceitual direta com a vida por meio das vivências, o que ratifica a defesa da noção que a vivência não comunga com sistematizações conceituais e, dessa forma, se apresenta como contraconceito da razão (Viesenteiner, 2013).

Diante desses argumentos, fica inviável o esforço generalista de possibilitar uma mesma vivência aos estudantes, visto que até mesmo vivências corriqueiras são estritamente individuais a ponto de serem distintas para cada pessoa. Não há como findar a vivência nem tampouco mensurar seus efeitos por meios racionais. 


\section{pro.posições}

$e$-ISSN 1980-6248

http://dx.doi.org/10.1590/1980-6248-2019-0047

Quanto ao mais da vida, as chamadas "vivências", qual de nós pode levá-las a sério? Ou ter tempo para elas? Nas experiências presentes, receio, estamos sempre "ausentes": nelas não temos nosso coração - para elas não temos ouvidos. Antes, como alguém divinamente disperso e imerso em si, a quem os sinos acabam de estrondear no ouvido as doze batidas do meio-dia, e súbito acorda e se pergunta "o que foi que soou?", também nós por vezes abrimos depois os ouvidos e perguntamos, surpresos e perplexos inteiramente, "o que foi que vivemos?", e também "quem somos realmente?", e em seguida contamos, depois como disse, as doze vibrantes batidas em nossa vivência, da nossa vida, nosso ser - ah! e contamos errado... Pois continuamos necessariamente estranhos nós mesmos, não nos compreendemos, temos que nos mal entender, a nós se aplicará para sempre a frase: "Cada qual é o mais distante de si mesmo" - para nós mesmos somos "homens do desconhecimento" (Nietzsche, 2009, p. 7).

O esforço para instrumentalizar, tornar consciente ou racionalizar a vivência é herdeiro de uma vontade de verdade. Uma tentativa inglória de correspondência entre o mundo real e o discurso criado sobre o mundo. O mundo real não se permite traduzir em palavras. No mundo da vida tudo deixa de ser o que é e varia, de acordo com o fluxo do devir, como diria o filósofo Heráclito. No mundo real tudo é impermanente. A busca e o desejo da verdade são incompatíveis com a fugacidade do mundo. Aqui bem cabe a indagação de Nietzsche (2016): “o que são, então, nossas vivências? São muito mais aquilo que nelas pomos do que o que nelas se acha! Ou deveríamos até dizer que nelas não se acha nada? Que viver é inventar?” (p. 88).

A aceitação e, sobretudo, a afirmação do mundo e seus paroxismos requer um esforço constante e diário para que não sucumbamos aos ditames da razão nem a sentidos teístas ou que pretendem explicar a existência. Afirmar o acaso e o instante é tarefa árdua e perigosa para que seja possível o dizer "sim" à vida sem construções e idealizações frustradas de um mundo ideal.

Recorremos mais uma vez a Nietzsche (2016): "tudo isso que chamamos de consciência é um comentário, mais ou menos fantástico, sobre um texto não sabido, talvez não 'sabível', porém sentido" (p. 87). Conscientes dessa dimensão fantástica e inventiva, questionamos os rígidos pilares e os valores tradicionalmente vigentes. Refutamos os discursos com pretensões universalizantes, afirmamos as variadas formas de produção do conhecimento e problematizamos os limites da razão. Isso posto, fazemos uso e nos ancoramos na noção de vivência com o intuito de descolonizar essa tirania imediata da razão e descolar a racionalidade da mediação do corpo com as sensações.

A Educação Física culturalmente orientada não abre mão das vivências das práticas corporais. Reafirma a importância de brincar a brincadeira, dançar a dança, lutar a luta, praticar o esporte ou a ginástica, tendo como ponto de partida a ocorrência social dessas práticas 


\section{pro.posıções}

http://dx.doi.org/10.1590/1980-6248-2019-0047

$e$-ISSN 1980-6248

culturais. Escapando da armadilha da racionalização escolar, os momentos de vivência são pura expressão da gestualidade a partir das referências que os estudantes possuem. Seria contraditório um "ensinar a fazer". O foco reside muito mais no fazer como já fez ou como acha que deve fazer. É esse brincar, dançar, lutar, praticar o esporte ou ginástica descompromissados com o pensar sobre que potencializa a dimensão estética, o sentir na pele. Mas o contato com discursos variados sobre as práticas corporais também se configura como vivência no CC: assistir a um filme, ler um texto, ouvir uma explicação do professor ou do colega, realizar uma visita ao local onde a manifestação acontece, entre tantas outras possibilidades, configuram-se como portas de entrada para novas e inusitadas formas de ver e sentir a brincadeira, dança, luta, esporte ou ginástica, que modificam, questionam ou desestabilizam os primeiros olhares e as sensações anteriores.

A proposta aqui pretendida é a implosão das idealizações e, consequentemente, da herança da visão metafísica de mundo para uma dimensão imanente e vitalista sem recorrer a posições transcendentais por mais sedutoras e vistosas que se apresentem. Fundamentados na filosofia nietzschiana, ratificamos o caráter decadente, doentio e redutor que esses elementos exerceram e ainda exercem sobre a vida. O convite de aproximar o conceito de vivência explorado na obra de Nietzsche ao CC significa associar e, sobretudo, afirmar a potência do contato, do embate e do conflito inerente ao viver. Desse modo, amplia-se a possibilidade de abertura para uma dimensão do imponderável, do inapreensível. Adentrar nesse contexto é enxergar a potência disparadora da vivência.

\section{Em Foucault...}

Para tratar propriamente a noção de experiência, pensemos nos processos de subjetivação que compreendem a verdade sobre o sujeito, as práticas de controle sobre essa verdade e a sua subjetividade. O filósofo francês considera a existência de um duplo jogo que garante a constituição dos sujeitos. Nesse jogo, de um lado está a submissão dos sujeitos a determinadas condições de poder e, de outro, a produção de uma subjetividade, de um agir do próprio indivíduo sobre as condições de submissão (Foucault, 2014a). 


\section{pro.posições}

http://dx.doi.org/10.1590/1980-6248-2019-0047

\section{$e$-ISSN 1980-6248}

De modo a compreender essa colocação, pensemos na relação intrínseca entre verdade e poder (Foucault, 2014c). O poder que age sobre os sujeitos precisa de uma relação de verdade para se legitimar. Ou seja, o poder precisa ser compreendido pelos outros como verdadeiro.

Quando Foucault se refere ao termo poder, de certo faz referência às relações de poder, consideradas como algo que se exerce sobre si ou sobre os outros, que é imanente e intencional. O poder se inscreve nos corpos sociais por meio de dispositivos instrumentais que produzem sujeitos que atuam em contextos específicos. As relações de poder ocorrem por meio da produção e da troca de signos (verdades); desse modo, ele só existe em ato. A existência do poder implica a articulação de dois elementos que lhes são imprescindíveis: reconhecer o sujeito sobre o qual se exerce o poder como sujeito de ação, isto é, um sujeito que também é capaz de exercer o poder, o que implica uma relação entre sujeitos livres, fora de uma relação de dominação, de violência; e reconhecer que, nessa relação, se abre um campo de reações diversas e efeitos possíveis que produzem diversos modos de comportamento e, com isso, impactam as formas de atuação do poder. O exercício do poder é a condução das condutas, é governar o campo de atuação dos sujeitos (Foucault, 2014b).

Foucault (2014c) propõe, então, que compreendamos o governo dos vivos pela verdade. Esse controle do sujeito por meio dessas verdades é considerado como processo de assujeitamento, o que irá garantir com que os indivíduos sejam reconhecidos e se reconheçam em determinadas ordens discursivas. Por exemplo, um professor não é reconhecido e tampouco se reconhece enquanto sujeito professor se não assume determinadas formas de poder do próprio lugar da docência. Com o aluno não é diferente, pois para se reconhecer e ser reconhecido como tal, terá que assumir determinadas formas de poder desse lugar. E é somente estando assujeitado a determinadas formas de poder que o sujeito é capaz de exercitar o agir sobre si mesmo de maneira a produzir outros modos de ser professor ou aluno, isto é, outras formas de subjetividade. Aqui, considera-se também que a vinculação voluntária a uma verdade implica uma vinculação involuntária a determinada forma de poder que gere a ordem discursiva do que se quer tomar por verdade.

Tomemos a forma como o cenário neoliberal ganha espaço nos discursos pedagógicos da atualidade, haja vista as metodologias ativas, o professor reflexivo, o aluno protagonista. Eles sugerem o desenvolvimento de uma autogestão, no campo da subjetividade, dos comportamentos dos envolvidos com a prática. Rose (1998) argumenta que as capacidades 


\section{pro.posıções}

http://dx.doi.org/10.1590/1980-6248-2019-0047

$e$-ISSN 1980-6248

subjetivas dos indivíduos no contexto de organização política neoliberal são incorporadas aos objetivos do poder público. Ou seja, ao aderirmos voluntariamente às práticas pedagógicas que têm como objetivo orientar indivíduos para noções de gestão do eu, vislumbrando atender às necessidades do mercado de trabalho, nos submetemos involuntariamente à lógica neoliberal do governo dos corpos.

Foucault (2014c) propõe uma atitude de recusa do poder, não no sentido de acabar com ele, mas de assumir que nenhum poder é legitimo intrinsecamente. Ora, não há como ficar de fora do uso do poder, mas pode-se colocá-lo em questão, desconfiar das verdades e das estruturas que o mantém enquanto real em si. Aqui o autor se depara com outra problemática, qual seja: a do sujeito como produtor de si mesmo. A partir do momento em que se percebe a condição produtiva do poder, que o poder não é determinista e verdadeiro por si só, percebese a capacidade dos indivíduos como produtores de poder.

Adentramos, então, na questão da experiência. Baseados em Foucault (2014b), pensamos a produção de si, o exercício do sujeito de constituição da própria subjetividade como exercício de aquisição de experiências. Assim, criar estratégias para produção de outras formas de poder é parte do processo do experienciar, experimentar.

Não se pode captar a experiência a partir de uma lógica da ação, a partir de uma reflexão do sujeito sobre si mesmo enquanto sujeito agente, a partir de uma teoria das condições de possibilidade da ação, mas a partir de uma lógica da paixão, uma reflexão do sujeito sobre si mesmo enquanto sujeito passional (Larrosa Bondía, 2002, p. 26).

É preciso estar exposto a determinada verdade para que se compreenda sua produção como experiência e, só assim, sejamos transformados por ela. $\mathrm{O}$ discurso da autoridade sobre o ser professor serve de ilustração. A autoridade é vista como condição fundamental para condução da prática pedagógica na instituição escolar, ao mesmo tempo que captura o ser docente de forma a tornar-se condição necessária à existência da docência. Logo, a docência implica o exercício da autoridade. Sem compreender o que produz esse discurso, professoras e professores agem a partir dele, perpetuando uma mesma lógica que massacra outras formas de existência - como o ser criança. Parar, perceber e analisar de que forma se produz esse discurso permite a localização de possíveis escapes à captura pelo autoritarismo docente, possibilitando a produção de outras formas de existir professora e professor. 


\section{pro.posıções}

$e$-ISSN 1980-6248

http://dx.doi.org/10.1590/1980-6248-2019-0047

Larrosa Bondía (2002) emprega a palavra paixão de três formas para entender a exposição à experiência. A primeira associada ao padecimento, ao sujeito paciente. A paixão assume o padecimento como um viver. Assumir de forma pública, como se ao assumir determinada paixão já fossemos capazes de compreender as verdades que nos tornam sujeitos dentro de determinada ordem discursiva e, assim, assumir dentro do contexto determinadas formas de poder.

Em Foucault (2017), isso acontece pelas práticas de si. A invenção de práticas pelos sujeitos permite o exercício de compreender os processos de construção das verdades que os constituem. Essas práticas só são possíveis por meio de um cuidado de si $^{7}$, entendido como forma de nos conhecermos enquanto sujeitos. Cada indivíduo, ao cuidar de si, é capaz de produzir técnicas que produzem outras formas de poder, outras formas de conduzir-se em determinados contextos.

Para Larrosa Bondía (2002), a paixão também pode referir-se a uma responsabilidade em relação ao outro, não desvinculada da liberdade. Compreende-se, a partir de Foucault (2017), que liberdade é refletida de uma ética. Se as verdades assumidas não possuem legitimidade intrínseca, busca-se escapar o máximo possível das relações de dominação para/com outro e para/consigo mesmo. Entende-se, assim, a experiência como possibilidade de prática de liberdade. Mediante a noção da liberdade problematizada como ética e da impossibilidade de escaparmos das relações de poder, devemos administrá-las sem nos submetermos, tampouco submetendo os outros, às relações de dominação.

Cuidar de si com vistas à liberdade requer atenção redobrada para o modo pelo qual gerenciamos os usos do poder para que não o façamos para a dominação. Nossa vontade de verdade para entender as coisas do mundo nos leva à vontade de poder. O que significa nossa vontade de domínio. Sem esse cuidado, não há práticas de liberdade, porque somos prisioneiros de determinada força que nos governa. Se nos deixarmos tomar pelo abuso do poder, tornamonos tiranos de nós mesmos e dos outros. Se a tirania não permite a liberdade, ela cerra o movimento, a expressão, o pensamento. Ela não deixa ninguém ser livre. Ao sermos tiranos de

\footnotetext{
${ }^{7}$ Para tratar do cuidado de si, Foucault (2014b) busca inspiração nos gregos antigos que tinham esse preceito como um dos grandes princípios da cidade, uma grande regra de conduta social. Os sujeitos precisavam conhecer-se e, assim, cuidar-se, governar-se para conduzirem bem a si e também aos outros. Foucault não pretende trazer esse cuidado dos gregos para os tempos atuais, mas pensar a partir deles práticas que nos permitam compreender as teias de poder que nos constituem como sujeitos e, ao mesmo tempo, possibilitar a produção de outras teias, possibilitar as práticas de liberdade.
} 


\section{pro.posições}

$e$-ISSN 1980-6248

http://dx.doi.org/10.1590/1980-6248-2019-0047

nós mesmos, somos escravos de uma excessiva vontade de poder que nos toma. O que impede uma vida ética. Praticar a liberdade é assumir um posicionamento político sobre as coisas, assumir que o outro também produz e é produzido de outras formas.

Por fim, Larrosa Bondía (2002) também entende paixão como a experiência do amor:

o sujeito apaixonado não é outra coisa e não quer ser outra coisa que não a paixão. Daí, talvez, a tensão que a paixão extrema suporta entre vida e morte. A paixão tem uma relação intrínseca com a morte, ela se desenvolve no horizonte da morte, mas de uma morte que é querida e desejada como verdadeira vida, como a única coisa que vale a pena viver, e às vezes como condição de possibilidade de todo renascimento (p. 26).

Aí reside a capacidade transformadora da experiência, sendo que, ao deixar-se afetar pelas coisas por meio desse exercício de si e da escolha em assumir e recusar determinadas formas de poder, produz-se outras formas de ser, outras formas de vida. Compreende-se, então, a experiência como algo que transforma o indivíduo, algo que impede que permaneça o mesmo, que o arranca de um estado criado pelo processo de assujeitamento, abrindo-o para uma dissolução de si (Brandão, 2016).

Ao trazer esse debate para o CC da Educação Física, considera-se que as práticas pedagógicas constroem e modificam as relações dos sujeitos consigo mesmos e com os outros, construindo também experiências (Larrosa Bondía, 1995).

Amparado em Foucault, Nunes (2018) acrescenta a experiência de si como uma das dimensões convencionais no planejamento do ensino culturalmente orientado. $O$ trabalho durante as aulas pode levar os envolvidos à compreensão de que as práticas e modos de vida são fruto de produções; de que, ao reconhecer que as produções discursivas sobre determinada prática corporal ou sobre os seus sujeitos não possuem uma legitimidade intrínseca, eles podem assumir e/ou recusar determinadas verdades; e, também, de que eles podem produzir outras formas de se relacionar com as práticas corporais e com seus representantes. Isso, em relação a pressupostos éticos que garantem o afastamento das relações de dominação que determinados grupos exercem sobre outros.

Trata-se, aqui, de compreender as aulas enquanto um acontecimento. Trata-se de tomálas como espaços em que há possibilidade de aquisição de experiências proporcionadas por encontros entre diferentes formas de existência. Ao trabalharmos com os princípios ético- 


\section{pro.posições}

$e$-ISSN 1980-6248

http://dx.doi.org/10.1590/1980-6248-2019-0047

políticos $^{8}$ do CC, chamamos atenção para a ancoragem social dos conhecimentos e a afirmação da diferença. O primeiro garante que as práticas corporais sejam abordadas na escola da maneira como são significadas fora dela; isso possibilita que o grupo envolvido com as aulas compreenda as relações de força que permeiam e constituem a própria prática. O segundo, na direção do primeiro, visa possibilitar que os elementos da cultura e os praticantes das práticas corporais estudadas possam compreender a identidade de si, dos outros e das coisas como uma amálgama, para pensar em abertura para outra coisa, transgredir os limites normativos impostos pela identidade e, assim, afirmar outras possibilidades de ser e fazer. Com isso, os sujeitos que compõem a aula também se tornam produtores daquilo que estudam, ao passo que a imersão na prática os torna sujeitos dessa prática (Nunes, 2018).

O trabalho pedagógico influenciado por esses princípios possibilita o acesso à experiência de duas maneiras: (i) por meio da preocupação em articular os temas ${ }^{9}$ e conhecimentos com as práticas já significadas pelos envolvidos com a aula; e (ii) por meio da afirmação de outras formas de existir das práticas da cultura corporal e dos envolvidos que não aquelas concebidas como verdadeiras e hegemônicas. Assim, a prática do basquetebol como forma de lazer que acontece na quadra do bairro aos finais de semana abastece as aulas como tema, garantindo que o jogo jogado nesse cenário aconteça no espaço da escola de modo a ampliar e aprofundar a leitura dos códigos que determinam a prática naquele contexto, ao mesmo tempo em que, ao longo dos estudos sobre o basquetebol, outras formas de existir da modalidade também surjam por meio de questionamentos suscitados pelos estudantes, desestabilizando essencialismos.

Também levamos em consideração nesses dois princípios uma preocupação com o presente, considerando que a ancoragem social está delimitada por determinado espaço e tempo. A afirmação da diferença, por sua vez, se faz presente de forma pontual durante as aulas, sendo que não existe um estado pleno de afirmação da diferença dentro dos sistemas de relação de poder que se deslocam e modificam. O que, diante deste princípio, abre a possibilidade para que cada aula promova a aquisição de diferentes experiências, criando saídas para a constituição de outras formas de ser sujeito e, também, outros modos de fazer e dizer sobre as práticas

\footnotetext{
${ }^{8}$ Não se trata de um guia, um manual externo apartado da prática pedagógica e de seus sujeitos.

9 O termo "tema" sugere um estudo ampliado e aprofundado sobre os objetos tratados durante as aulas. É por meio das investigações temáticas que professores e alunos identificam, interpretam e modificam discursos produzidos sobre determinadas práticas corporais e seus sujeitos e se aproximam de uma compreensão comprometida com o modo como se produz as formas de ver o mundo (Santos \& Neira, 2016).
} 


\section{pro.posições}

http://dx.doi.org/10.1590/1980-6248-2019-0047

$e$-ISSN 1980-6248

tematizadas e seus representantes. Propomos, então, pensar, a partir das aulas de Educação Física, em uma estética da existência em direção à construção da experiência de si.

\section{Considerando...}

... tudo o que foi colocado, é possível afirmar que não há um estado permanente de liberdade no qual atuamos em todas as circunstâncias sobre o nosso ser sujeito. A estética da existência nos ajuda a pensar em uma experiência do agora, o que implica a abertura para a vivência, para a vida. A aula é singular para cada sujeito, e as forças que o atravessam em alguns contextos são as mesmas e em outros não. Pensar no agora implica entender a aula como um acontecimento que a tudo e a todos transforma por meio das relações estabelecidas, e pensar nessa experiência também implica compreender que os indivíduos que a compõem são outros a cada dia, nunca os mesmos, sempre diferentes. A experiência de si transgride os limites dados pelo objeto de estudo, pelos conhecimentos sobre a prática. Ela se dá de forma que a relação entre práticas e sujeitos modifica a relação do sujeito consigo mesmo.

Retomemos a questão do cuidado de si para conhecer-se. O conhecer-se implica compreender as concepções que constituem o "si", concepções de mundo, de sociedade, de família, de infância, de trabalho, de corpo etc. Ser um sujeito de experiências, construir a experiência de si, pressupõe localizar essas questões e as transformar, de forma a melhor conduzir um ser sujeito, permitindo, também, que o outro produza sua própria forma de se conduzir, afirmando assim formas de existir.

Um trabalho nesse caminho pressupõe expor os sujeitos a eles mesmos em cada uma das aulas, de forma a desestabilizar certezas, incomodar e inquietar, até que surjam perguntas e possamos atuar sobre elas. $O$ perguntar possibilita criar. Quando questionamos e problematizamos, abrimos um leque de saídas, acessamos inúmeras respostas, e o experimentar dessas respostas nos modifica, modificando a relação que estabelecemos com o mundo.

Tomar a vivência e a experiência de si nos termos aqui explicitados pode favorecer que as aulas de Educação Física se constituam em espaços de resistência às imposições castradoras da vida que a racionalidade política neoliberal quer impor. Quem sabe, ela inspire seus sujeitos a potencializar possibilidades transgressoras desses limites em si, na escola, na vida. 


\section{pro.posıções}

http://dx.doi.org/10.1590/1980-6248-2019-0047

$e$-ISSN 1980-6248

\section{Referências}

Brandão, R. T. P. (2016). Experiência e transformação de si: Foucault e a estetização da vida. Interespaço: Revista de Geografia e Interdisciplinaridade, 2(4), 81-96. doi:10.18766/24466549/interespaco.v2n4p81-96

Dewey, J. (2002). A escola e a sociedade: a criança e o currículo. Lisboa: Relógio d'Água.

Drucker, P. (1999). A sociedade pós-capitalista. São Paulo: Pioneira.

Escudero, N. T. G. (2001). Avaliação da aprendizagem em Educaşão Física na perspectiva cultural: uma escrita autopoiética. Dissertação de Mestrado, Universidade de São Paulo, São Paulo.

Foucault, M. (2008). O nascimento da biopolítica. São Paulo: Martins Fontes.

Foucault, M. (2014a). Do governo dos vivos: curso Collège de France (1979-1980). São Paulo: Martins Fontes.

Foucault, M. (2014b). Sujeito e o poder. In M. B. Motta (Org.), Genealogia da ética, subjetividade e sexualidade (Ditos \& Escritos, num. 9, pp. 264-296). Rio de Janeiro: Forense Universitária.

Foucault, M. (2014c). Técnicas de si. In M. B. Motta (Org.), Genealogia da ética, subjetividade e sexualidade (Ditos \& Escritos, num. 9, pp. 118-140). Rio de Janeiro: Forense Universitária.

Foucault, M. (2017). A ética do cuidado de si como prática da liberdade. In M. B. Motta (Org.), Ética, sexualidade e política (3a ed., Ditos \& Escritos, num. 5, pp. 258-280). Rio de Janeiro: Forense Universitária.

Husserl, E. (1996). A crise da bumanidade europeia e a filosofia (2a ed.). Porto Alegre: Edipucrs.

Larrosa Bondía, J. (1995) Tecnologias do eu e educação. In T. T. Silva (Org.), O sujeito da educação: estudos foucaultianos (pp. 35-86). Petrópolis: Vozes.

Larrosa Bondía, J. (2002). Notas sobre a experiência e o saber da experiência. Revista Brasileira de Educação, (19), 20-28. doi:10.1590/S1413-24782002000100003

Lima, M. E. (2007). A Educação Física no projeto político-pedagógico: espaço de participação e reconhecimento da cultura corporal dos alunos. Dissertação de Mestrado, Universidade de São Paulo, São Paulo. 


\section{pro.posições}

http://dx.doi.org/10.1590/1980-6248-2019-0047

$e$-ISSN 1980-6248

Locke, J. (1999). Ensaio acerca do entendimento bumano. São Paulo: Editora Nova Cultural.

Müller, A. (2016). A avaliação no currículo cultural da Educação Física: o papel do registro na reorientação das rotas. Dissertação de Mestrado, Universidade de São Paulo, São Paulo.

Neira, M. G. (2011). Educação Física. São Paulo: Blucher.

Neira, M. G., \& Nunes, M. L. F. (2006). Pedagogia da cultura corporal: crítica e alternativas. São Paulo: Phorte.

Neira, M. G., \& Nunes, M. L. F. (2009a). Educaşão Física, currículo e cultura. São Paulo: Phorte.

Neira, M. G., \& Nunes, M. L. F. (2009b). Praticando estudos culturais na Educação Física. São Paulo: Yendis.

Nietzsche, F. (2005). Assim falou Zaratustra. Rio de Janeiro: Civilização Brasileira.

Nietzsche, F. (2009). Genealogia da moral. São Paulo: Companhia das Letras.

Nietzsche, F. (2012). A Gaia Ciência. São Paulo: Companhia das Letras.

Nietzsche, F. (2016). Aurora: reflexões sobre os preconceitos morais. São Paulo: Companhia das Letras.

Noguera-Ramírez, C. E. (2011). Pedagogia e governamentalidade: ou da Modernidade como uma sociedade educativa. Belo Horizonte: Autêntica.

Nunes, M. L. F. (2018). Planejando a viagem ao desconhecido: o plano de ensino e o currículo cultural de Educação Física. In C. Fernandes (Org.), Ensino Fundamental: Planejamento da prática pedagógica: revelando desafios, tecendo ideias (pp. 77-115). Curitiba: Appris.

Perrenoud, P. (2000). Dez novas competências para ensinar: convite à viagem. Porto Alegre: Artes Médicas.

Popkewitz, T. (2004). A reforma como administração social da criança: globalização do conhecimento e do poder. In N. Burbules, \& C. A. Torres (Orgs.), Globalização e educaşão: perspectivas críticas (pp. 107-125). Porto Alegre: Artes Médicas.

Rose, N. (1998). Governando a alma: a formação do eu privado. In T. T. Silva (Org.), Liberdades reguladas: a pedagogia construtivista e outras formas de governo do eu (pp. 30-45). Petrópolis: Vozes.

Santos, I. L., \& Neira, M. G. (2016). A tematização no ensino da Educação Física. In M. G. Neira (Org.), Educação Física cultural (pp. 149-165). São Paulo: Blucher. 


\section{pro.posições}

http://dx.doi.org/10.1590/1980-6248-2019-0047

\section{$e$-ISSN 1980-6248}

Silva, T. T. (1999). Documentos de identidade: uma introdução às teorias do currículo. Belo Horizonte: Autêntica.

Viesenteiner, J. L. (2013). O conceito de vivência (Erlebnis) em Nietzsche: gênese, significado e recepção. Kriterion, 54(127), 141-155. doi:10.1590/S0100-512X2013000100008

\section{Referências consultadas}

Foucault, M. (2010). A bermenêutica do sujeito: curso dado no Collège de France (1981-1982) (3a ed.). São Paulo: Martins Fontes.

Dados da submissão:

Submetido à avaliação em 01 de abril de 2019; aceito para publicação em 13 de junho de 2019.

\section{Autor correspondente:}

Universidade Estadual de Campinas - Educação Física e Humanidades, Avenida Érico Veríssimo, 701, São Paulo,Campinas, Brasil,13083-851,mario.nunes@fef.unicamp.br 